\title{
THE USE OF ARTIFICIAL NEURAL NETWORK TO OPTIMIZE THE pH RESPONSE RANGE OF CHLOROPHENOL RED
}

\author{
F. Wong, M. Ahmad* and L.Y. Heng \\ School of Chemical Sciences and Food Technology, \\ Faculty Science and Technology, National University of Malaysia, \\ 43600 Bangi, Selangor Darul Ehsan, Malaysia
}

Received 12 March 2003, Accepted 22 May 2003

\begin{abstract}
Artificial Neural Network (ANN) had been used in this study to extend the response range of the $\mathrm{pH}$ indicator. The input from absorbance values of the absorbance spectra of chlorophenol red at different $\mathrm{pH}$ was used to train the ANN. During the training process, the coefficient values of the ANN will be adjusted to obtain the desire output. In this research, back propagation algorithm had been used for optimizing the response range of the $\mathrm{pH}$ indicator chlorophenol red in solution. The result indicates that the use of ANN enable the $\mathrm{pH}$ response range to be extended from 4.8-6.8 to 1.0-10.0.
\end{abstract}

Keywords : Artificial neural network, back-propagation algorithm, pH indicator,chlorophenol red.

\section{INTRODUCTION}

Chlorophenol red is a pH indicator, which gradually changes its colour over a range called "visual transition interval" 1 . Most of the $\mathrm{pH}$ indicators determine the $\mathrm{pH}$ changes indirectly in limited linear dynamic range, often 2-4 pH units only. Chlorophenol red indicator changes its colour from yellow to purple in a narrow interval of 4.0-7.0 $\mathrm{pH}$ units. To solve this problem especially in optical fiber optic $\mathrm{pH}$ sensor research, a lot of approach has been used such as using multiple $\mathrm{pH}$ indicators ${ }^{2,3}$, the use of indicators with multiple steps of acid dissociation and ANN technique ${ }^{4-6}$.

The original works on ANN were published more than 50 years ago by McCulloch and Pitts ${ }^{7,8}$ and Webb ${ }^{9}$. Lately, ANN has been shown to provide a superior alternative mechanism for modeling non-linear systems ${ }^{10-14}$. Application of ANNs is similar to conventional non-linear modeling techniques that require a model-structure design and parameter-estimating cycle to calibrate the model but ANNs use more general modeling approach, i.e. model structure need not to be defined explicitly ${ }^{12}$.

*Corresponding author-email: andong@pkrisc.cc.ukm.my 
In this paper, a multiplayer feed-forward ANN will be applied to a series of absorbance spectra generated from the $\mathrm{pH}$-sensitive indicator solution, chlorophenol red (CPR). The main objective was to extend the $\mathrm{pH}$ response range of the $\mathrm{CPR} \mathrm{pH}$ indicator while at the same time maintaining the prediction error at the acceptable level.

\section{EXPERIMENTAL}

\section{Apparatus}

All the absorption spectra were measured by using Varians Cary 100 UV-VIS spectrophotometer. The $\mathrm{pH}$ of the buffer solution was measured with an Ecomet $\mathrm{pH} / \mathrm{mV} / \mathrm{Temp} \mathrm{P} 25$ meter.

\section{Reagents}

All the reagents were used as received without any further purification. Tris- $\mathrm{HCl}(0.05 \mathrm{M})$ buffer solution was prepared by following standard procedure ${ }^{15}$. An appropriate amount of tris (hydroxymethyl) aminomethane (Fluka Chemika) salt was dissolve in deionized water (Water Deionized $\mathrm{E}$ - Pure Barnstead). Then, the tris- $\mathrm{HCl}$ buffers were prepared in different $\mathrm{pH}$ that range from $\mathrm{pH}$ 1-14 by adding hydrochloric acid or sodium hydroxide to the buffer solution to decrease or increase the $\mathrm{pH}$, respectively. On the other hand, the $\mathrm{pH}$ indicator, CPR solution $\left(2.06 \times 10^{-5} \mathrm{M}\right)$ was prepared by dissolving $4.01 \mathrm{mg}$ CPR salt (Riedel-De Haen) in deionized water and the solution was made to $250 \mathrm{~mL}$ volumetric flask by using deionized water.

Total volumes of $6.0 \mathrm{~mL}$ tris-HCl buffer solution and $3.0 \mathrm{~mL}$ chlorophenol red solution was added into volumetric flask $(10 \mathrm{~mL})$ and deionized water was added into the flask until it reaches the $10 \mathrm{~mL}$ level. Then, the absorbance spectrum of each solution was recorded by using UV-VIS spectrophotometer at wavelength range from 350 to $610 \mathrm{~nm}$. The same procedure was repeated for other buffer solution with $\mathrm{pH}$ range from $\mathrm{pH}$ 1-14. Absorbance value at the wavelength of $375,433,486,530,575,595$ and $605 \mathrm{~nm}$ of each spectrum was selected for the ANN training purpose.

\section{Artificial neural network and training}

The training of ANN was carried out using Mathlab, a three layer back-propagation (BP) ANN program running in Microsoft Windows 98 on a $200 \mathrm{MHz}$ personal computer in conjunction with Microsoft Excel 5.0. The inputs consists of seven neuron which corresponding to the absorption values measured at selected wavelength of 375, 433, 486, 530, 575, 595 and $605 \mathrm{~nm}$. Meanwhile, the output layer involves a single neuron representing the $\mathrm{pH}$.

A sets of $7 \mathrm{pH}(1,3,5,7,8,9,10)$ of input was introduced to the network and optimization of the network was done by changing the parameter of the network such as the learning rate, amount of hidden layer and number of epochs. After the training, the outputs ( $\mathrm{pH}$ value) were compared with the actual valued. The purpose of the optimization is to get the closest value of $\mathrm{pH}$ between the predicted and the actual value.

The predictions of calibration data was done by introducing a set ( $\mathrm{pH} 4.0,5.5,6.0,6.5$ and 8.5) of calibration data to the optimized network and the outputs for the network were evaluated by comparing the predicted value with the actual $\mathrm{pH}$ value measured by using the conventional $\mathrm{pH}$ 
glass electrode. If the outputs value and the actual value were close enough, then the training will be saved. Otherwise, the whole optimization process will be repeated by changing the parameter of the network.

\section{RESULT AND DISCUSSION}

\section{Determination of training input}

Figure 1 shows the three-dimensional and two-dimentional spectra of the chlorophenol red $\mathrm{pH}$ indicator measured at the $\mathrm{pH}$ range of 1-10. As shown in Figure 1A, the maximum absorption peak changes from $435 \mathrm{~nm}$ to $575 \mathrm{~nm}$ when $\mathrm{pH}$ increased. Figure 1B shows this changes more clearly where when $\mathrm{pH}$ increased, the absorption value at $435 \mathrm{~nm}$ decreased whereas the absorption value at $575 \mathrm{~nm}$ increased. Also, an isobestic point was observed in this spectrum at the wavelength of $480 \mathrm{~nm}$. Figure 2 shows the plot of the indicator absorbance values versus $\mathrm{pH}$ values at two different wavelengths of $575 \mathrm{~nm}$ and $433 \mathrm{~nm}$. As shown, the absorbance values at $433 \mathrm{~nm}$ decreased with increased $\mathrm{pH}$. On the other hand, at $575 \mathrm{~nm}$ absorbance value increased with increasing of $\mathrm{pH}$ value. All the absorbance value from $\mathrm{pH}$ 1-10 was use for ANN training purpose. The training of $\mathrm{pH}$ between $\mathrm{pH}$ 11-14 was not done because when the absorbance data of $\mathrm{pH}$ 11-14 was introduced to the network, the ANN was unable to be optimized well and the error was appear to be very high.

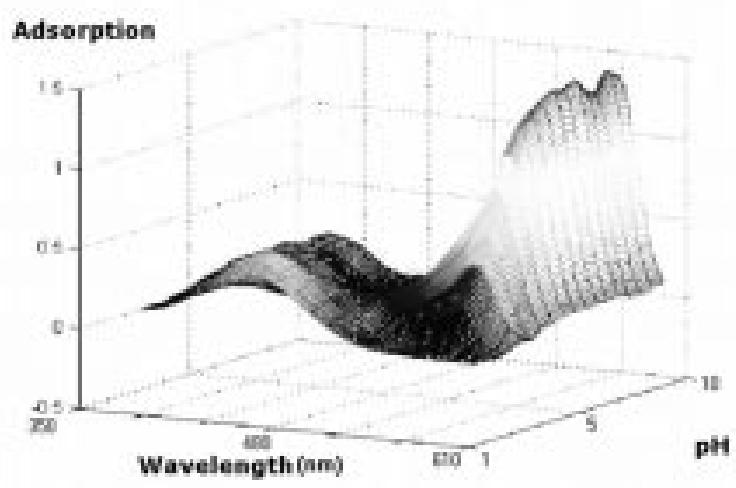

Figure 1 : Three-dimensional (A) and two-dimensional (B) spectra of the chlorophenol red indicator at various $\mathrm{pH}$ values. 


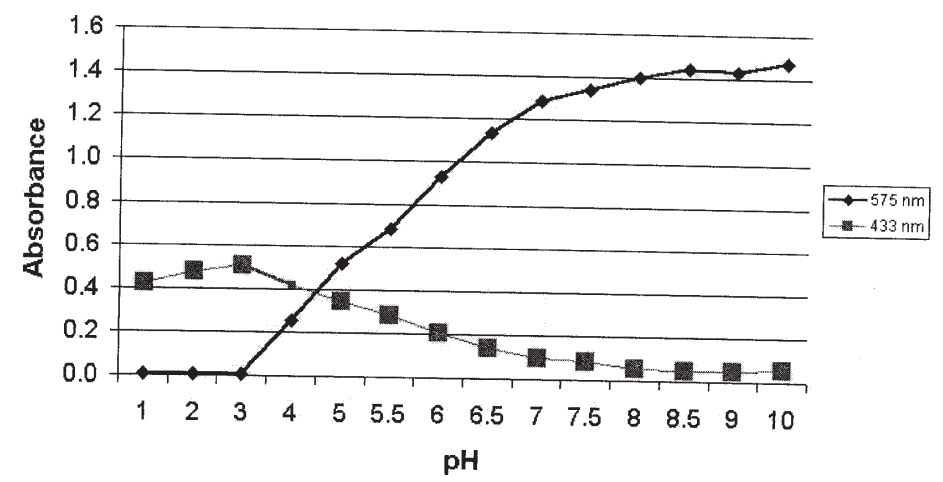

Figure 2 : The absorbance of the CPR at single wavelength of $433 \mathrm{~nm}$ and $575 \mathrm{~nm}$ versus $\mathrm{pH}$.

\section{Training of ANN}

In many ANN applications, which have been previously reported (4-6), learning rate parameter was not optimized when optimizing the ANN. In general, a high value for learning rate accelerates training, but it can easily lead to oscillations around the minimum. However, setting of learning rate to some low value causes an increase in the number of training epochs ${ }^{16}$. Learning rate near zero results in slow learning and in contrast, a learning rate near 1.0 results in fast learning. Learning is a procedure for modifying the weights and biases of a network ${ }^{17}$. As shown in Figure 3, the sum-squared error (SSE) increased when the learning rate become faster. However, when comparing the output of the network with the actual value of $\mathrm{pH}$ for both first and second sets of output, it shows that learning rate of 0.001 produced better prediction when compared to the output. During optimization of the learning rate, the number of epochs and the hidden layer were fixed at 10,000 and 25 , respectively.

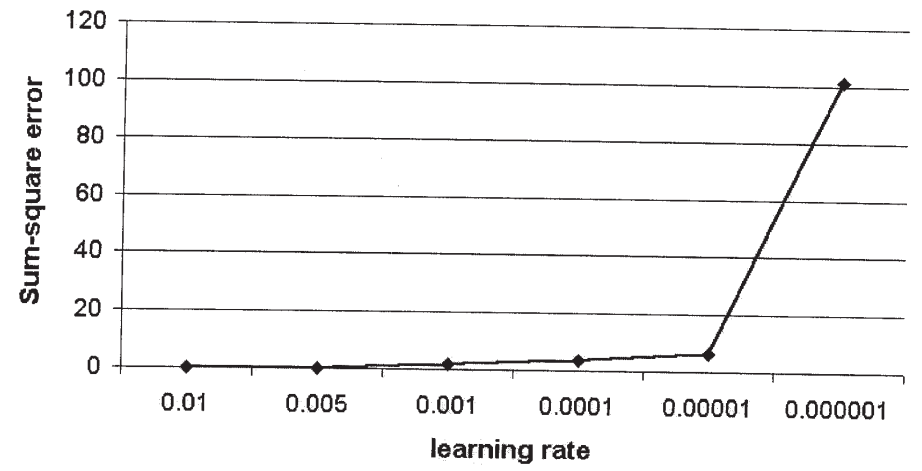

Figure 3 : Sum-squared error versus learning rate for ANN with 25 neurons in the hidden layers and 10,000 epochs.

To optimize the number of neurons in hidden layer, the learning rate was maintain at 0.001 whereas the number of epochs was maintained at 10,000. As shown in Figure 4, the sumsquared error decreased when the number of neuron in hidden layer increased. When the 
numbers of neurons in the hidden layer are in the range of 15 to 30 neurons, the output produced better prediction values when compared to the actual $\mathrm{pH}$ value. For predictions training data fitting, it was generally observed that the smaller the SSE, the closer the output value to the actual value. However, when using the same SSE value for prediction of calibration data, the predicted value was not close to the actual value.

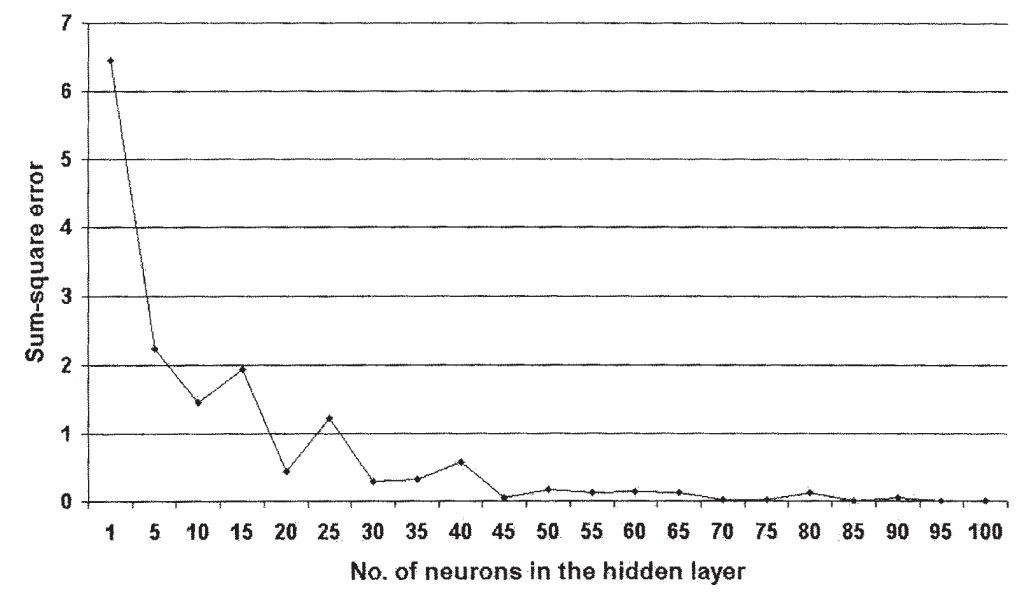

Figure 4: Sum-squared error versus number of neurons in the hidden layer for ANN with learning rate of 0.001 and 10,000 epochs.

Figure 5 shows the plot of the SSE values at different number of training cycle or epochs. As shown, the SSE decreased when the number of epochs increased. This observation agreed well with the results on optimization of hidden layer, which has been previously reported by Musa et al. [5]. In this study, it was found that if the number of epochs is higher than 10,000 epochs; the less accurate result was produced when this network was used for prediction of calibration data. Therefore, it was concluded in this study that the best prediction was obtained when learning rate of $0.001,25$ neurons of hidden layer and 10,000 epochs were used.

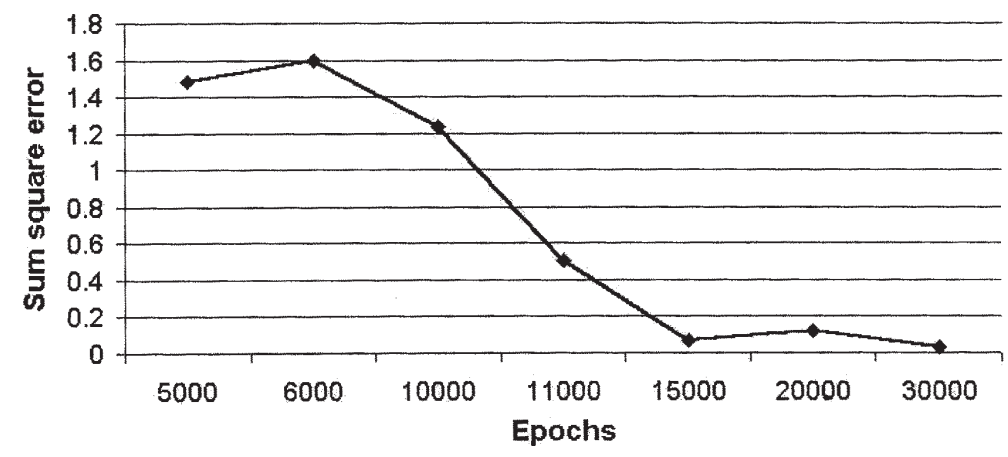

Figure 5 : Sum-squared error versus number of epochs for ANN with learning rate of 0.001 and 25 neurons in the hidden layers. 
Table 1 and Table 2 show the prediction value for training data fitting and calibration data, respectively. From Table 1, all of the predicted values are close to the actual value with average percentage error of $1.4 \%$. On the other hand, Table 2 also shows that the predicted values for calibration data are close to the actual values and only $\mathrm{pH} 5.5$ shows slightly higher percentage error of $4.3 \%$. The average percentage error is only $1.9 \%$. As shown in Figure 6, the predicted

Table 1 : Predictions of training data fitting of the network at learning rate of 0.001, 25 neurons in the hidden layers and 10,000 epochs.

\begin{tabular}{|l|l|l|l|l|l|l|l|}
\hline $\begin{array}{l}\text { Actual } \mathrm{pH} \\
\text { value }\end{array}$ & 1 & 3 & 5 & 7 & 8 & 9 & 10 \\
\hline $\begin{array}{l}\text { Predicted } \\
\mathrm{pH} \text { value }\end{array}$ & 1.015 & 3.018 & 5.042 & 7.162 & 8.208 & 9.075 & 10.128 \\
\hline $\begin{array}{l}\text { Percentage } \\
\text { error } \\
(\%)\end{array}$ & 1.5 & 0.6 & 0.9 & 2.3 & 2.6 & 0.8 & 1.3 \\
\hline
\end{tabular}

Table 2 : Predictions of calibration data of the network at learning rate of 0.001, 25 neurons in the hidden layers and 10,000 epochs.

\begin{tabular}{|l|c|c|c|c|c|}
\hline $\begin{array}{l}\text { Actual } \mathrm{pH} \\
\text { value }\end{array}$ & 4 & 5.5 & 6 & 6.5 & 8.5 \\
\hline $\begin{array}{l}\text { Predicted } \\
\mathrm{pH} \text { value }\end{array}$ & 4.0094 & 5.2654 & 5.9476 & 6.6939 & 8.4068 \\
\hline $\begin{array}{l}\text { Percentage } \\
\text { error } \\
(\%)\end{array}$ & 0.2 & 4.3 & 0.9 & 3.0 & 1.1 \\
\hline
\end{tabular}

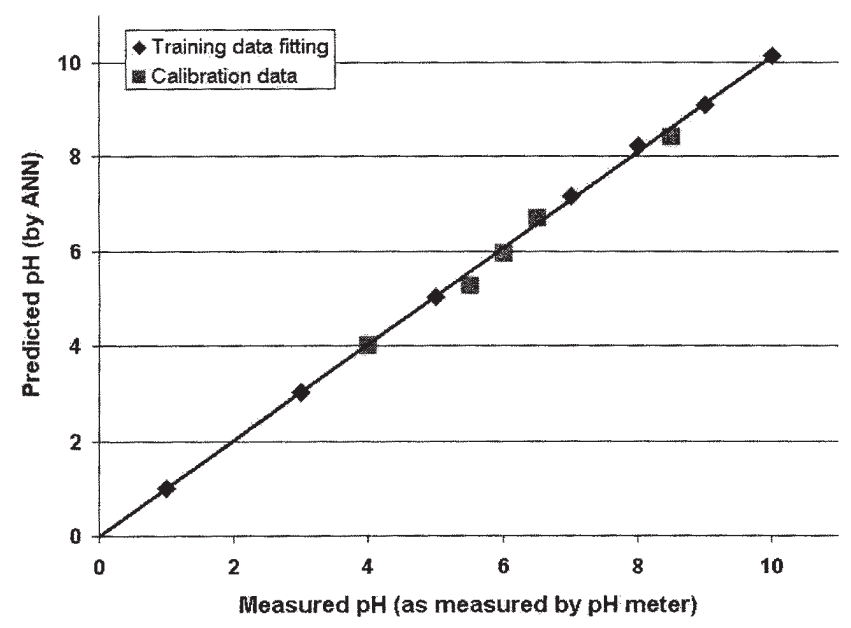

Figure 6 : Validation plot of test data prediction for the network with learning rate of 0.001, 25 neurons in the hidden layers and 10,000 epochs. 
values of optimized ANN are close to the actual data (measured by $\mathrm{pH}$ meter) and it was found that ANN had successfully extended the $\mathrm{pH}$ response range of CPR from limited $\mathrm{pH}$ range of 4.8-6.8 to determine $\mathrm{pH}$ range of 1-10.

\section{CONCLUSION}

The use of ANN for extending the useful response range of $\mathrm{pH}$ indicator chlorophenol red has been demonstrated in this study. The useful response range of the indicator was found to increase from 4.8-6.8 to 1.0-10.0 by using the optimized ANN with learning rate of $0.001,25$ hidden neurons and 10,000 epochs.

\section{ACKNOWLEDGEMENTS}

The authors would like to acknowledge the Ministry of Science, Technology and Environment of Malaysia for providing the research grant coded IRPA 09-03-03-006.

\section{REFERENCES}

1. Bishop, E. (1972) Indicators. Pergamon Press, Oxford.

2. Gupta, B.D. and Sharma D.K. (1997), Optics Communications, vol.140, pp. 32-35.

3. Gupta, B.D. and Sharma S. (1998), Optics Communications, vol.154, pp. 282-284.

4. Taib, M.N., Andres, R. and Narayanaswamy, (1996), Anal. Chim. Acta, vol. 330, pp. 31-40.

5. Musa, A., Suah, F.B.M. and Taib M.N. (2001), Malaysian Journal of Chemistry, vol. 3, no. 1, pp. 29-34.

6. Suah, F.B.M., Musa A. and Taib, M.N. (2001), Malaysia Journal of Analytical Sciences, vol. 7, no. 1, pp. 121-128.

7. McCulloch, W.S. and Pitts, W. (1943), Bull. Math. Biophys., vol. 5, p. 115.

8. Pitts, W. and McCulloch, W.S. (1947). How we know universals: the perception of auditory and visual forms, Bull. Math. Biophys., vol . 9, pp. 127.

9. Webb, D.O. (1949) The Organization Behavior, Wiley, New York.

10. Narendra, K. and Parthasarathy, K. (1990), IEEE Trans. Neural Netwoks, vol. 1, pp. 4-27.

11. Yuzhu, H., Gewen, Z., Jihong, K., Yingxiang, D., Fang, H. and Jianhua, G. (1996), Journal of Chromatography A, vol. 734, no.2, pp. 259-270.

12. Taib, M.N. and Narayanaswamy, R. (1997), Sensors Actuators B, pp.38-39, pp. 365-370.

13. Brook, T.E., Taib, M.N. and Narayanaswamy, R. (1997), Sensors Actuators B, pp. 38-39, pp. 272-276.

14. Vuckovic, A., Radivojevic, V., Chen, A.C.N. and Popovic, D. (2002), Medical Engineering \& Physics, vol. 24, no. 5, pp. 349-360.

15. Dean, J.A. (1989) Chemist Ready Reference Handbook, McGraw-Hill Inc., New York.

16. Cirovic, D.A. (1997), Trends in Analytical Chemistry, vol. 16, no. 3, pp. 148-155.

17. Hagan, M.T., Demuth, H.B. and Beale, M. (1996), Neural Network Design. PWS Publishing Company, Boston. 